\title{
Percepção de idosos sobre o papel do Psicólogo em Instituições de Longa Permanência
}

Elderly's perception of the role of the Psycohologist at Homes for the Aged

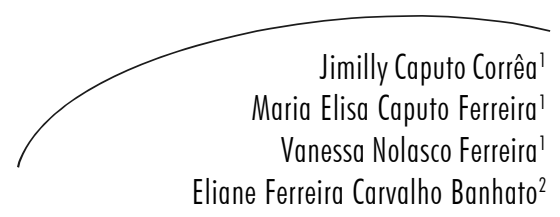

Resumo

Este trabalho se propôs a descrever a percepção de idosos institucionalizados sobre o papel do profissional psicólogo junto à população abrigada das Instituições de Longa Permanência para Idosos (ILPI) da cidade de Juiz de ForaMG. O universo da pesquisa abrangeu as instituições cuidadoras e cadastradas junto ao Conselho Municipal do Idoso da referida localidade. Quanto à metodologia, procedeu-se a estudo qualitativo exploratório utilizando a Análise de Conteúdo na perspectiva de Bardin como ferramenta para o tratamento dos dados. Os critérios de inclusão utilizados foram: 1) ser residente em ILPI; 2) ter 60 ou mais anos de idade; 3) aceitar participar; e 4) ser capaz de responder às perguntas formuladas. Constitui-se amostra por conveniência de 34 idosos que apresentaram as seguintes representações acerca do papel do psicólogo: relevância e pertinência de seu trabalho, não percebendo a presença de pontos negativos no trabalho deste profissional nas ILPIs. Identificou-se ainda que as áreas de atuação psicológica mais apontadas foram as relacionadas à prevenção, diagnóstico e tratamento dos residentes naqueles locais.

\section{Abstract}

This study aimed to describe the perception of institutionalized elderly about the role of the psychologist with the population housed at homes for the aged in the city of Juiz de Fora-MG. The research covered the caregivers and institutions registered with the City Council of the Elderly of that city. Regarding methodology, it is a qualitative exploratory study using content analysis at Bardin's perspective to treat the data. The inclusion criteria were: 1) living at a Home for the Aged; 2) be 60 years old or more; 3) agree to participate in the research; and 4) be able to answer the questions. A convenience sample comprised 34 subjects who presented the follow representations about the role of the

Programa de Pós-graduação em Psicologia, Departamento de Psicologia. Universidade Federal de Juiz de Fora. Juiz de Fora, MG.

2 Curso de Psicologia, Departamento de Psicologia. Centro de Ensino Superior de Juiz de Fora. Juiz de Fora, MG.

Correspondência / Correspondence

Jimilly Caputo Corrêa

E-mail: jimillyc@hotmail.com
Palavras-chave:

Envelhecimento. ILPI.

Psicólogo.

Key words: Aging. Homes for the Aged. Psychologist. 
psychologist: relevance and pertinence of the job, not perceiving negative aspects at the work of these professional at the Homes for the Aged. It was also found that psychological practice areas mentioned most frequently were related to prevention, diagnosis and treatment of those who live in those places.

\section{INTRODUÇÃO}

A revolução tecnológica das últimas décadas vem promovendo significativa transformação nas condições socioeconômicas e de saúde em todo o mundo. Em consequência, a diminuição das taxas de mortalidade e de natalidade acarreta o fenômeno de transição demográfica, com o aumento significativo no número de idosos. ${ }^{1}$

No Brasil o envelhecimento é uma realidade, sendo que $11,3 \%$ da população brasileira são formados por idosos. Esse rápido crescimento dezenas de milhões - foi mais observado a partir do ano de 2005, quando as pessoas nascidas nas décadas de 1940 a 1950 começaram a atingir os 60 anos de idade. ${ }^{2}$

Até o início do século XX, a expectativa de vida era de 33,7 anos. No início da década de 50, atingiu a marca dos 43,2 anos e, em 2000, alcançou 68,5 anos. $E$ as projeções apontam para 72 anos em 2025. ${ }^{3}$ Além disso, é significativo o percentual de pessoas com idade entre 80 ou mais anos. $\mathrm{O}$ número de centenários está projetado para aumentar 15 vezes, passando de 145 mil, em 1999, para 2,2 milhões de indivíduos em 2050. ${ }^{4}$

Mas, se é certo que se vive mais anos, objetivo perseguido pelo homem durante séculos, também é verdade que tal realidade é desafiadora. É grande o impacto social e econômico decorrente do crescimento populacional. Como exemplo, citase a necessidade de anexar o processo de promoção integrada de políticas aos aspectos ligados a moradia, nutrição, educação, igualdade de oportunidades entre os sexos, etc. ${ }^{5}$

Sob a ótica da economia, sobretudo na Previdência e na assistência à saúde, a atuação preventiva e curativa representa significativo impacto na política financeira. Desse modo, as questões ligadas à maior expectativa de vida levam a importantes mudanças na conduta social. ${ }^{6} \mathrm{Citam}-$ se ainda os riscos ambientais, oriundos da falta de acessibilidade e da vida urbana não adaptada ao idoso, e os riscos de saúde, que podem levar à perda de autonomia e capacidade funcional, devido a doenças crônicas e degenerativas. ${ }^{7}$ Assim, envelhecer de forma saudável nos dias atuais traz consigo a necessidade de desenvolver estratégias de adaptação à nova configuração social decorrente das profundas mudanças observadas em nossa sociedade.

Nessa perspectiva, o envelhecimento como fator natural tem-se mostrado, nas últimas décadas, objeto de atenção de todas as áreas profissionais e da cultura sócio-educativa em nível mundial. Diversos órgãos brasileiros, governamentais e nãogovernamentais, têm se dedicado ao estudo sistematizado da população idosa com o objetivo de melhor conhecer suas necessidades e elaborar políticas de saúde e sociais adequadas. ${ }^{4}$

A responsabilidade pelo idoso é atribuída fundamental e legalmente à família, como apontam os estudos de Debert. ${ }^{8}$ Muitas vezes, no entanto, os familiares se veem impedidos de exercer tal tarefa, devido a suas obrigações particulares, à necessidade imperiosa de trabalhar para o próprio sustento, bem como para garantir o bem-estar do parente idoso. Estes fatores, na maioria das vezes, são determinantes para que a família opte pela institucionalização. Assim, com base nas realidades do mundo contemporâneo e nas necessidades de assistência e provisão dessa população, a Lei $\mathrm{n}^{\mathrm{o}} 8.842 / 94$, e sua regulamentação no Decreto $\mathrm{n}^{\circ} 1.948 / 96$, asseguram aos indivíduos com 60 ou mais anos de idade, uma velhice assistida, na inexistência do grupo familiar, abandono e carência de recursos. ${ }^{9}$ Cabe ao Estado o encaminhamento dos idosos às Instituições de Longa Permanência para Idosos 
(ILPIs), desde que comprovadas as impossibilidades e recursos da família em assisti-lo.

Historicamente, as instituições asilares são vistas de forma preconceituosa pela sociedade e recebem conotação inadequada para a sua atividade e rotina. Nem sempre, no entanto, elas são o local onde se abandona ou se negligencia a velhice. Apesar disso, é certo que deixar a condição de morar sozinho ou em família para a condição de asilado é uma mudança que exige esforço de

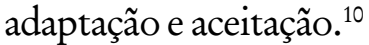

A transição geralmente representa um impacto para o idoso, pela perda de referências e do sentimento de pertença, trazendo repercussões no estado emocional, nas relações e na saúde de quem vive asilado. A partir do asilamento nas ILPIs, a possibilidade de o idoso administrar seu tempo, seu espaço, suas decisões e relações se apresentam, em geral, perdidas, e seu querer se torna o querer da instituição, fazendo com que submeta sua vontade à vontade e às decisões administrativas da mesma. ${ }^{10}$

Dentre os inúmeros aspectos necessários para a manutenção da boa qualidade dos serviços prestados por essas instituições, é importante ressaltar o papel do profissional psicólogo. Com a função primordial de possibilitar aos idosos asilados a busca de um sentido para suas experiências de vida e o enfrentamento da velhice sob a ótica psíquica, o psicólogo deve promover, nesses locais, atividades em grupo como um recurso terapêutico intermediando construções de laços sociais e afetivos. ${ }^{11}$

A observação prática aponta, no entanto, que ainda são poucas as instituições que contam com a presença desse profissional em seu quadro de trabalhadores. E essa situação pode acabar comprometendo a percepção que os idosos institucionalizados possam ter do papel desse profissional em uma ILPI.

O presente trabalho teve o objetivo geral de identificar as percepções que os idosos institucionalizados na cidade de Juiz de ForaMG possuem sobre a importância do trabalho do psicólogo em instituições. De modo específico, pretendeu-se levantar o percentual de profissionais psicólogos em exercício profissional em ILPIs da referida cidade.

\section{METODOLOGIA}

O presente estudo utilizou o referencial teórico qualitativo exploratório, a fim de buscar conhecer as especificidades da percepção dos idosos residentes nas IPLIs frente ao papel do psicólogo na instituição. O referido delineamento foi escolhido a fim de tornar os procedimentos metodológicos claros e objetivos e permitir apurar os dados com o rigor objetivo, sem perder o caráter subjetivo dos mesmos. ${ }^{12}$

\section{Participantes}

O público-alvo desta pesquisa foram os idosos residentes em ILPIs selecionados por conveniência, ou seja, a partir do cadastro no Conselho Municipal do Idoso da cidade de Juiz de Fora-MG. Os critérios de inclusão na amostra foram: 1) ser residente em ILPI; 2) ter 60 ou mais anos de idade; 3) aceitar participar; e 4) ser capaz de responder às perguntas formuladas. Foram excluídos os idosos que se recusaram a participar do estudo ou que foram apontados pelas instituições como comprometidos cognitiva e funcionalmente. Desse modo, o estudo contou com um total de 34 idosos, de ambos os sexos. As idades foram compreendidas entre 60 a 95 anos com média de 76,18 (DP = 10,30) anos.

\section{Instrumentos}

Realizou-se entrevista semiestruturada composta por questões abertas que investigaram a percepção dos idosos sobre o papel do psicólogo na instituição, e fechadas que versavam sobre os dados sociodemográficos dos mesmos idosos.

\section{Procedimento}

Para obter um padrão adequado sobre as funções do psicólogo e seus atributos em ILPIs, construiu-se um questionário, que foi submetido 
a um conselho de juízes, constituído por seis psicólogos especializados na área organizacional e institucional, que julgaram quais seriam as principais funções do psicólogo em instituições asilares.

A entrevista com os juízes abordou os seguintes questionamentos: quais são as atribuições do psicólogo na instituição de longa permanência para idosos? Assim, eles respondiam sobre suas funções na instituição e o modo de realizá-las na mesma, ou como as interpretavam.

As perguntas relacionadas ao papel do psicólogo na instituição foram: Qual a importância do psicólogo na instituição de longa permanência para idosos? Quais os pontos positivos de se ter um psicólogo na instituição? Quais ospontos negativos de se ter um psicólogo na instituição? Deste modo, os idosos respondiam como eles reconheciam a importância do profissional naquela ILPI.

Quanto à seleção das instituições, realizou-se inicialmente um levantamento das ILPIs cadastradas no Conselho Municipal do Idoso de Juiz de Fora-MG. Todas elas foram visitadas (11 no total) e, nesse momento, identificaram-se as que possuíam o psicólogo em seu quadro de profissionais.

A partir daí, foram incluídas no presente estudo as que estavam regularmente reconhecidas como ILPI, tanto de caráter público quanto privado, e sem fins lucrativos; as que possuíam cadastro junto ao Conselho Municipal do Idoso de Juiz de Fora-MG e as que contavam com o trabalho do psicólogo em seu quadro profissional. Sob esse critério, foram identificadas seis instituições, das quais uma possuía psicólogo, mas os idosos não eram autônomos, ou seja, não respondiam por si, e as autorizações com os familiares eram restritas. Desse modo, somente cinco instituições participaram da pesquisa.

As instituições recebiam uma cópia do projeto e uma carta solicitando permissão para o desenvolvimento do estudo. O consentimento era referendado pela entrega de um termo de aceite por parte da instituição. As visitas às ILPIs selecionadas ocorreram em setembro e outubro de 2009, após aprovação no Comitê de Ética em Pesquisa do Centro de Ensino Superior de Juiz de Fora-CES/JF, sob o número 245.18.09.2009.

Todos os idosos foram informados sobre os objetivos da pesquisa e solicitados a participarem da mesma. As pessoas que concordavam em colaborar assinavam o Termo de Consentimento Livre e Esclarecido.

\section{Análise dos Dados}

O questionário demográfico e as questões relativas à percepção do papel do psicólogo nas ILPIs foram aplicados individualmente. $\mathrm{O}$ pesquisador lia as questões em voz alta e, em seguida, os participantes eram solicitados a responderem, havendo gravação e transcrição integral da entrevista, conforme previsto no termo de consentimento livre e esclarecido. Posteriormente, essas questões foram avaliadas segundo a técnica de Análise de Conteúdo. ${ }^{12}$

Os dados foram analisados procedendo-se, em primeiro lugar, a uma leitura flutuante de todo o material transcrito. Em seguida, foi feita uma préanálise e criado um perfil dos participantes. $\mathrm{O}$ terceiro passo foi o recorte, agregação e enumeração dos dados, permitindo esclarecer os indícios de categoria. Passou-se à categorização propriamente dita, construindo-se, assim, um corpus de análise que levou à elaboração de indicadores para a discussão final e posterior inferência, comparando-se os resultados obtidos com as referências presentes na literatura. ${ }^{12}$

\section{RESULTADOS}

Identificaram-se 11 ILPIs cadastradas junto ao Conselho Municipal do Idoso, das quais apenas $45,4 \%(n=6)$ apresentavam psicólogos em exercício profissional.

Foram entrevistados 34 idosos. A média de idade encontrada foi de 76,29 anos (DP=10,09). Da amostra total, $64,7 \%(n=22)$ eram do sexo feminino, com média etária igual a 77,27 anos $(\mathrm{DP}=8,69)$. No grupo masculino, a média etária 
foi de 74,50 anos (DP=12,50). Quando avaliados por faixas etárias, verificou-se que o grupo de idosos jovens (60-69 anos) foi constituído por 11 idosos com média de 64,91 $(\mathrm{DP}=3,48)$ anos. $\mathrm{O}$ grupo de idosos com 70-79 anos (idosos-médios) foi formado por oito pessoas com média de idade de 73,63 (DP = 3,42) enquanto os idosos-idosos (igual ou acima de 80 anos) totalizaram 15 indivíduos e a média de idade foi de 86,07 $(\mathrm{DP}=4,18)$ anos.

Quanto à escolaridade, a média de anos estudados foi de 6,00 anos $(\mathrm{DP}=3,86)$. É importante destacar que, da amostra total, $5,9 \%$ $(\mathrm{n}=2)$ eram analfabetos, enquanto $17,6 \%(\mathrm{n}=6)$ possuíam 12 ou mais anos de escolaridade. Quando avaliado por gênero, verificou-se que a média de escolaridade entre as mulheres foi de 6,50 anos $(\mathrm{DP}=3,78)$, enquanto o grupo masculino obteve média de 5,08 (DP= 4,01) anos.

No que se refere ao estado civil, foi predominante o número de viúvos $(52,9 \% ; n=18)$. A frequência de solteiros foi de $32,4 \%(n=11)$. Chamou atenção a presença de uma pessoa ser casada $(2,9 \%)$, porém seu cônjuge morava fora do ambiente da instituição.

Para avaliar a percepção dos idosos quanto à presença do psicólogo, fez-se a seguinte pergunta: "Qual a importância do psicólogo na Instituição de Longa Permanência para Idosos?”. As respostas variaram segundo as categorias:
1) Ajudar/dar assistência: quando os idosos falam em ajuda, é relacionado à administração de medicação, dar assistência às pessoas que não estão conscientes no sentido de evitar cenas desagradáveis, ajudar nas tarefas cotidianas.

2) Conversar e orientar: bater-papo, aliviar no momento de sofrimento, ter uma palavra em todos os momentos.

3) Falar pelos outros: transmitir algo que o idoso não consegue falar, seja porque não tem instrução ou devido as limitações.

4) Manter o equilíbrio da instituição: manter a boa convivência entre as pessoas.

As categorias para a amostra total com as respectivas frequências estão descritas na tabela 1. ${ }^{13}$ Destacou-se que um idoso confundiu a psicóloga com a fisioterapeuta, dizendo que ela "mexia com os braços e as pernas"; foi preciso explicar quem era a psicóloga (falar o nome e características, como por exemplo, "mexe com a cabeça"), mas mesmo assim ele não soube falar da importância da mesma. De acordo com a psicóloga da instituição, os idosos não têm claramente definidos os papéis dos profissionais, pois todos estão sempre vestidos da mesma maneira, de jalecos brancos, e não conseguem fazer a distinção dos mesmos, explicando que seria necessário falar de psicólogo como "aquele que mexe com a cabeça”.

Tabela 1 - Frequência de respostas da amostra total. ${ }^{13}$ Juiz de Fora, MG, 2009. ( $\left.N=34\right)$

\begin{tabular}{lcc}
\hline \multicolumn{1}{c}{ Categorias } & $\mathrm{n}$ & $\%$ \\
\hline Conversar e orientar & 20 & 58,82 \\
Ajudar/Dar assistência & 11 & 32,35 \\
Resolver problemas & 4 & 11,76 \\
Incentivar & 3 & 8,82 \\
Vigiar & 2 & 5,88 \\
Falar pelos outros & 2 & 5,88 \\
Chamar a atenção para algo errado & 2 & 5,88 \\
Manter o equilíbrio da instituição & 2 & 5,88 \\
\hline
\end{tabular}


É interessante apontar que seis pessoas responderam não precisar de psicólogo, não terem contato e que psicólogo é para quem não está consciente, ou seja, “o psicólogo é para quem vacila"; sempre ressaltando que "eu não estou assim".

A maior frequência de respostas nas mulheres foi ajudar (11), orientar (9) e conversar (8). Com relação aos homens foram bem diversas, como: boa, ajudar, chamar atenção para algo errado, resolver problemas e conversar. Isso pode ser visto nas falas coletadas e a seguir expostas:

"As pessoas que tem problemas, ela dá conselho, orienta, ajuda as pessoas que as vezes já não tem a cabeça boa"(W.73a.).

"Orientar para ajudar no que é melhor para ele, dar uma dica”(M.T.60a.).

"A psicóloga vai conversar com todos pra saber cada um o que que precisa. Orientações de acordo com o desenvolvimento, a pessoa irmelhorando"(M. 91a.).

Ainda sobre ter um psicólogo na instituição, $70,59 \%(\mathrm{n}=24)$ da amostra geral responderam não perceberem pontos negativos; $8,82 \%(n=3)$ reclamaram da falta de atividades ou cuidados específicos, como por exemplo, artesanato, boa comida, cuidados na hora do banho; duas pessoas não souberam responder e as respostas com menor frequência (uma vez) foram: ser chamado a atenção, o psicólogo não poder conversar com cada um separadamente, ou seja, atendimento individual; e não estar satisfeito em estar no asilo. As falas dos idosos ilustram as informações:

"Ah, o que ele ajuda aqui é, faz, reunião com a gente né, então ele é muito bom porisso, porque ele ajuda a tomar conta né, de certas coisas erradas que dá né, então é bom éporisso"(M. 77a.).

"Elapode conversar com, com, bom aí com o chefe, e conversar com as cozinheiras"(W.73a.).

$\mathrm{Na}$ fala das mulheres, 59,09\% $(\mathrm{n}=13)$ disseram não ter pontos negativos quanto ao trabalho do psicólogo; no entanto, o restante da amostra apontou este aspecto como chamar atenção, criticar a instituição, não ter conversa individual e não gostar de estar no asilo. Já com os homens, $91,67 \%(\mathrm{n}=11)$ responderam não ter ponto negativo e um idoso reclamou de faltar algo na instituição. Os pontos positivos ditos nas entrevistas são mostrados na tabela $2 .^{13}$

Tabela 2 - Pontos positivos de acordo com as respostas dos idosos da amostra total. ${ }^{13}$ Juiz de Fora, $\mathrm{MG}, 2009$. $(\mathrm{N}=34)$

\begin{tabular}{llc}
\hline \multicolumn{1}{c}{ Categorias } & $\mathrm{n}$ & $\%$ \\
\hline Orientar & 8 & 23,53 \\
Conversar & 6 & 17,65 \\
Ajudar & 3 & 8,82 \\
Aconselhar & 4 & 11,76 \\
\hline
\end{tabular}

Para as mulheres, o ponto positivo é: orientar, $22,73 \%(\mathrm{n}=5) ; 13,64 \%(\mathrm{n}=3)$ responderam: dar conselho, ajudar, conversar. As falas menos frequentes foram: realizar reunião, explicar, festas, fazer o que o psicólogo estudou, unir, incentivar, apoiar, não deixar fazer coisa errada, ter trabalho em equipe. E respostas vagas: tudo de bom, muita coisa; além de: não ter e não saber. Do total de pessoas que responderam à pesquisa, as respostas de dez idosos do sexo masculino mais frequentes foram: aconselhar, muitas coisas, dar atenção, conversar, orientar. Conforme os participantes demonstraram nas falas:

"Ajuda, com problema do INPS, dinbeiro pra depositar"(A.66a.).

"Ajudar na harmonia das pessoas, respeito, atenção, compreensão, da sua idade, dos seus problemas" (J.A. 73a.). 
"É importante o trabalho da psicóloga com a assistente social, isso éfundamental e assim é o trabalho em equipe, eu acho, da psicóloga" (Z.85a.).

Outras atribuições que o psicólogo deve ter ao trabalhar numa instituição, colocadas pelos juízes, são: estudar aspectos psicológicos e psicopatológicos do envelhecimento; tratar de mudanças emocionais e cognitivas; fazer intervenções em problemas relacionados a doenças e dores crônicas, sendo estas intervenções em grupo, oficinas e individuais, além de trabalhar com a família; auxiliar os profissionais (principalmente os cuidadores) no manuseio com os residentes, a fim de que entendam a importância do diálogo nas suas atividades (por exemplo, falar o que irão fazer com o idoso); promover o convívio social, o bom relacionamento entre todos que ali estão (idosos, família, profissionais). Nas falas dos juízes, é possível verificar essas informações:

"O psicólogo pode atuar com enfoques diferentes dependendo das condicōes físicas e mentais do público que irá atender" (Juiz J.)

"Além das atribuicões de um profissional de psicologia, o setor desenvolve também ações paralelas com a finalidade de melhor atendimento e prestar maior segurança e assistência biopsicossocial ao interno atendido"(Juiz M.)

Algumas atribuições do psicólogo foram ditas pelos idosos e pelos juízes, outras foram comentadas apenas pelos juízes. De modo geral, elas dizem respeito aos serviços mais internos e burocráticos, não envolvendo o idoso diretamente. Talvez por isso, essas atribuições estão ausentes nas falas dos idosos, mas são papéis importantes para o funcionamento da instituição e o bom atendimento ao idoso. Exemplos de tais atividades seriam: admissão e entrevistas com idosos ingressantes na vaga, encaminhamentos, acolhimento e acompanhamento psicológico com o idoso durante o processo de adaptação, acompanhamento e evolução de internos, seleção de novos funcionários, treinamento e capacitação dos mesmos, atendimento ao público externo (estudantes, grupos religiosos, visitas de escolas), atuação no trabalho em rede (UBS, Departamento de Saúde da Terceira Idade, etc.), adequação da instituição ao Regulamento Técnico para o Funcionamento das Instituições de Longa Permanência para Idosos - RDC nº 283 , de setembro de 2005.

\section{DISCUSSÃO}

Notou-se que as respostas dos psicólogos das instituições quanto ao papel deste profissional numa ILPI são condizentes com as dos juízes, ou seja, quando foram perguntados "quais são as atribuições do psicólogo na instituição de longa permanência para idosos" estes responderam: organização de eventos, orientações, aconselhamento, fazer reuniões, ter responsabilidade de técnico (relações com gerência, dinheiro, telefonema), incentivar as capacidades dos idosos, realizar atividades para estimular a capacidade funcional e cognitiva, trabalho com equipe (fisioterapia), dinâmica de grupo.

O trabalho em equipe, encontrado na fala dos idosos, esteve em consonância com as respostas dos juízes, que relataram ser uma atribuição do psicólogo, além de ser encontrada na literatura ${ }^{14-}$ ${ }^{17}$ a importância de outros profissionais de outras áreas no trabalho em conjunto. Exemplo dessa atuação pode ser visto em organizações ligadas à saúde, como hospitais e instituições de longa permanência, onde o psicólogo pode atuar junto à própria equipe de saúde, trabalhando suas crenças e angústias em relação à velhice em geral e, em especial, aos significados de seu próprio processo de envelhecimento. É importante trabalhar essas questões junto aos profissionais de saúde, devido à influência que têm em suas vidas pessoais e à interferência que podem provocar no tipo de atendimento dado aos idosos. $^{15}$

No âmbito das instituições cuidadoras de idosos, a questão do atendimento interdisciplinar constitui um fato. ${ }^{16} \mathrm{O}$ trabalho do psicólogo contribui para a estruturação da equipe de trabalho ao exercer a possibilidade de escutar a demanda grupal e intervir em questões relativas à instituição. ${ }^{17}$ 
O que foi relatado pelos idosos e os juízes está de acordo com a literatura, ${ }^{15,17,18}$ quando se fala dos serviços de recursos humanos (seleção, treinamento), trabalho em equipe, dinâmicas, atendimento em grupo e individual, famílias, comunicação com a rede. A inclusão da família no atendimento ao idoso formou uma rica parceria, contribuindo para a desmistificação com relação à institucionalização e diminuição de preconceitos antes existentes nas famílias em que a prática ocorria. ${ }^{18}$

Com relação aos serviços de recursos humanos, tem-se "ofertas de serviços a idosos". ${ }^{19}$ Também pode ser verificado que estar no asilo é uma situação que incomoda alguns idosos, seja por querer estar em outro local ou por quererem comer coisas diferentes e tomar banho como tomavam antes das limitações. Verificam-se na literatura os diversos motivos da institucionalização. ${ }^{10}$

Observou-se, nas falas dos idosos, que o ponto positivo e a importância de ter um psicólogo se relacionam com momentos de promover atividades que de modo geral os favoreçam, seja com festas ou de maneira indireta (resolução de problemas, ações na gerência) para seu bem-estar, e o quão importante é a profissão do psicólogo, que os mantém em constante atividade. No entanto, de acordo com algumas falas dos entrevistados, o psicólogo ainda é confundido com profissionais de outras áreas ou os idosos nem percebem que naquela ILPI existe este profissional; e quando o psicólogo mantém contato com os idosos, nota-se a falta de conhecimento sobre o papel desse profissional.

De acordo com o artigo "A arte de cuidar do idoso: Gerontologia como profissão?”, 20 especialistas afirmam que não há o profissional da gerontologia "especializado", mas são o médico, o assistente social, o psicólogo, o enfermeiro e outros profissionais que compõem o atendimento conjunto de uma instituição de longa permanência; são eles que se "especializam" em gerontologia, acompanhamento e atendimento de paciente e da população idosa. Desta forma, pode haver confusão, por parte dos idosos, em distinguir os papéis de cada profissional dentro da instituição. ${ }^{20}$

O levantamento das instituições no Conselho Municipal do Idoso apontou que, até o momento são 11 as ILPIs cadastradas, sendo que duas se encontram com documentação pendente. Além disso, são seis as que se encontram em situação irregular e sob risco de serem fechadas, por não atingirem as expectativas de bom atendimento ao idoso ou não estarem estruturadas segundo as novas normas de funcionamento. É importante ressaltar que é baixo o percentual de ILPIs que apresentam o psicólogo em seu quadro regular de profissionais.

Nota-se que ainda há muitas instituições em que o papel de psicólogo é repassado a outros profissionais da saúde ou não existe; pode acontecer que, quando houver um profissional capacitado para desempenhar determinada tarefa, os idosos confundem as funções de cada um. Deste modo, as atividades de estimulação aos idosos ficam precárias, havendo necessidade de explorar mais este assunto através de mais pesquisas dedicadas a estudar como o papel dos psicólogos constitui um diferencial na qualidade de vida dos idosos em ILPIs, e também no âmbito institucional, envolvendo a equipe da instituição.

Observou-se que as pessoas com mais idade estão sendo cada vez mais institucionalizadas, em função das necessidades do próprio idoso ou das circunstâncias familiares. De modo geral, os idosos-idosos são mais institucionalizados e prevalentes nas ILPIs, conforme apontaram os dados do presente estudo, corroborando a literatura especializada. ${ }^{2,10,15,18,21}$

De acordo com a escolaridade, percebeu-se neste estudo que foram poucas as pessoas analfabetas institucionalizadas, o que é contrário aos dados descritos em estudos da área. ${ }^{22}$ Tal fato pode ser decorrente de uma tendência dos estudos na cidade de Juiz de Fora-MG para melhores condições de vida futura.

A viuvez apareceu na amostra como o estado civil predominante, mostrando que a 
institucionalização é vista como um recurso para quem não possui uma pessoa para compartilhar as situações da vida. Houve um predomínio de mulheres institucionalizadas, o que demonstra a feminização da velhice, que é uma manifestação do processo de transição de gênero que acompanha o envelhecimento populacional em curso em todo o mundo. ${ }^{23,24}$

\section{CONCLUSÃO}

O trabalho do profissional psicólogo dentro da instituição pode ser de grande importância para as pessoas que ali residem, na medida em que propicie melhores condições como autonomia, independência e aumento da autoestima dos idosos. Impulsiona-se assim a manutenção de um estilo de vida saudável, podendo reduzir a chance de ocorrência de condições que levam a patologias. Além de reforçar os recursos do próprio indivíduo para a preservação da saúde mental, estimula sua participação em atividades educacionais e sociais, a troca de apoio social, a criação de novos interesses e o estabelecimento de laços afetivos e apoia o engajamento em atividades que estimulem a criatividade, a sociabilidade e a participação comunitária, contribuindo para a realização de metas pessoais e dando um sentido pessoal à vida.

Destaca-se também o suporte que este profissional pode oferecer à instituição, de modo que as carências sejam supridas e se possível oferecer melhores recursos aos idosos. Assim os idosos entrevistados ressaltaram a importância do profissional da psicologia e apontaram que este realiza tarefas capazes de melhorar sua qualidade de vida.

Entretanto, ainda há uma confusão quanto aos papéis do psicólogo e de outros profissionais, podendo-se pensar se as pessoas que estão nas instituições já não fazem distinção entre as funções, ou se realmente há confusão quanto à atuação deste profissional. Com isso ressalta-se a importância de os psicólogos marcarem seu espaço profissional, para que sejam vistos de maneira útil e benéfica aos que ali estão e que deles necessitam. Para que essas ações se concretizem é necessário mudar atitudes, práticas e políticas, ocasionando mudanças no envelhecimento, favorecendo o idoso e criando oportunidades de desenvolvimento pessoal.

Dentre as limitações deste estudo, cita-se uma pequena amostragem decorrente de vários fatores. O primeiro motivo seria a falta de psicólogo no quadro de trabalhadores das instituições. Outro fator observado foi o grande número de idosos institucionalizados incapacitados de responder o protocolo de investigação.

Ainda são limitadas as pesquisas no âmbito institucional, e o incentivo a esses estudos poderá trazer contribuições significativas para o campo da psicologia e melhores maneiras de trabalhar com os idosos institucionalizados. 


\section{REFERÊNCIAS}

1. Papaléo-Netto M. Processo de envelhecimento e longevidade. In: Papaléo-Netto M. Tratado de Gerontologia. 2. ed. São Paulo: Atheneu; 2007.p.3-14.

2. Chaimowicz F; Greco DB. Dinâmica da institucionalização de idosos em Belo Horizonte. Rev. Saúde Pública 1999 out; 33 (5): 454-60.

3. Fundação Instituto Brasileiro de Geografia e Estatística(IBGE). Malha municipal digital do Brasil: situação em 2001. Rio de Janeiro: IBGE; 2004. Disponível em URL: < http:// www.ibge.gov.br/home/estatistica/populacao/ censo2000/migracao/ censo2000_migracao.pdf $>$.

4. Freitas EV. Demografia e epidemiologia do envelhecimento. In: Py L.; Pacheco JL, Goldeman SN. Tempo de envelhecer: percursos e dimensões psicossociais. Rio de Janeiro: Nau Editora; 2004. p. 19-35.

5. Camarano AA. Envelhecimento da população brasileira: uma contribuição demográfica. In: Freitas EV, PL; Neri AL, Cançado FAX.; Gorzoni, ML, Rocha SM. Tratado de Geriatria e Gerontologia. Rio de Janeiro: Guanabara Koogan; 2002. p. 58-71.

6. Ramos LR. Epidemiologia do Envelhecimento. In Freitas EV. Tratado de geriatria e gerontologia. Rio de Janeiro: Guanabara Koogan; 2002. p.383-93.

7. Quaresma MLB. Envelhecimento: questões de gênero. In: Corte B.; Mercadante EF, Arcuri IG. Envelhecimento e velhice: um guia para a vida. São Paulo: Vetor Editora; 2006. p.49-76.

8. Debert GG. A reinvenção da velhice: socialização e processos de privatização do envelhecimento. São Paulo: Edusp; 1999.

9. Brasil.Lei $\mathrm{n}^{\circ} 8.842$ Política Nacional do Idoso 4 jan 1994. Diário Oficial da União 5 jan 1994.

10. Perlini NMOG, Leite MT, Furini AC. Em busca de uma instituição para a pessoa idosa morar: motivos apontados por familiares. Rev Esc. Enferm USP 2007; 41(2): 229-36.

11. Alcântara AO. Velhos institucionalizados e família: entre abafos e desabafos. São Paulo: Editora Alínea; 2004.

12. Bardin L. Análise de conteúdo. Lisboa: Edições 70; 2009.

13. Corrêa JC. O papel do psicólogo por idosos institucionalizados. Juiz de fora Monografia [Trabalho de Conclusão de Curso]- Faculdade de Psicologia; 2009.
14. Papaléo Netto M. Gerontologia: a velhice e o envelhecimento em visão globalizada. São Paulo: Atheneu; 1996.

15. Neri AL. Contribuições da psicologia ao estudo e à intervenção no campo da velbice. Rev Brás Ciêncs Envelhec Humano [Acesso em 26 ago 2009. Disponivel em: http:// www.upf.tche.br/seer/index.php/rbceh/article/ viewFile/46/55

16. Lustosa MA. Atendimento ao paciente idoso. Rev. SBPH 2007 dez; 10(2):7-11. Disponível em: http://pepsic.bvs-psi.org.br/ scielo.php?script $=$ sci arttext\&pid $=$ S1516$08582007000200003 \& \overline{\mathrm{ln}} \mathrm{g}=\mathrm{es} \& \mathrm{nrm}=$

17. Lopes RGC, Barbieri NA, Gambale CA. Velhice contemporânea e atuação do psicólogo. In: Falcão DVS, Araújo LF. Psicologia do envelhecimento: relações sociais, bem-estar subjetivo e atuação profissional em contextos diferenciados. Campinas: Alínea; 2009. p. 195-213.

18. Creutzberg M, Gonçalves LHT, Sobottka EA. Instituição de longa permanência para idosos: a imagem que permanece. Contexto Enferm 2008 abr/jun; 17(2): 273-9

19. Neri AL. O que a psicologia pode oferecer ao estudo e à intervenção no campo do envelhecimento no Brasil, hoje. In: Neri AL. Yassuda MS. Velhice bem sucedida. Campinas: Papirus; 2004. p. 13-27.

20. Pavarini SCI, Mendiondo MSZ, Barham EJ, et al. A arte de cuidar do idoso: gerontologia como profissão? Context Enferm 2005 ; 14(3):398-402.[Acesso em 13 set 2009. Disponível em: http://www.scielo.br/pdf/tce/v14n3/ v14n3a11.pdf.

21. Khoury HTT, Rêgo RCCS, Silva JC, et al. Bemestar subjetivo de idosos residentes em instituições de longa permanência. In: Falcão DVS, Araújo LF. Psicologia do Envelhecimento: relações sociais, bem-estar subjetivo e atuação profissional em contextos diferenciados. Campina: Alínea; 2009, p. 103-118.

22. Araújo TCN, Alves MIC. Perfil da população idosa no Brasil. Textos sobre envelhecimento. Programas para a Terceira Idade: algumas reflexões. Rio de Janeiro: UNATI/UERJ 2000; 3 (3): 7-19.

23. Neri AL. Idosos no Brasil: vivências, desafios e expectativas na terceira idade. São Paulo: Fundação Perseu Abramo; 2007.

24. Neri AL. Palavras-chave em gerontologia. Campinas: Alínea; 2008. 